\title{
A living thick nanofibrous implant bifunctionalized with active growth factor and stem cells for bone regeneration
}

This article was published in the following Dove Press journal:

International Journal of Nanomedicine

4 February 2015

Number of times this article has been viewed

\author{
Sandy Eap ${ }^{1,2, *}$ \\ Laetitia Keller ${ }^{1-3, *}$ \\ Jessica Schiavi,2 \\ Olivier Huck ${ }^{1,2}$ \\ Leandro Jacomine ${ }^{4}$ \\ Florence Fioretti ${ }^{1,2}$ \\ Christian Gauthier ${ }^{4}$ \\ Victor Sebastian 1,3,5 \\ Pascale Schwinté 1,2 \\ Nadia Benkirane-Jessel ${ }^{1,2}$ \\ 'INSERM, UMR II09, Osteoarticular \\ and Dental Regenerative \\ Nanomedicine Laboratory, FMTS, \\ Faculté de Médecine, Strasbourg, \\ France; ${ }^{2}$ Faculté de Chirurgie Dentaire, \\ Université de Strasbourg, Strasbourg, \\ France; ${ }^{3}$ Department of Chemical \\ Engineering, Aragon Nanoscience \\ Institute, University of Zaragoza, \\ Zaragoza, Spain; ${ }^{4}$ CNRS (National \\ Center for Scientific Research), ICS \\ (Charles Sadron Institute), Strasbourg, \\ France; ${ }^{5}$ Networking Research Center \\ of Bioengineering, Biomaterials and \\ Nanomedicine, Zaragoza, Spain \\ *These authors contributed equally \\ to this work
}

\begin{abstract}
New-generation implants focus on robust, durable, and rapid tissue regeneration to shorten recovery times and decrease risks of postoperative complications for patients. Herein, we describe a new-generation thick nanofibrous implant functionalized with active containers of growth factors and stem cells for regenerative nanomedicine. A thick electrospun poly $(\varepsilon-$ caprolactone) nanofibrous implant (from $700 \mu \mathrm{m}$ to $1 \mathrm{~cm}$ thick) was functionalized with chitosan and bone morphogenetic protein BMP-7 as growth factor using layer-by-layer technology, producing fish scale-like chitosan/BMP-7 nanoreservoirs. This extracellular matrix-mimicking scaffold enabled in vitro colonization and bone regeneration by human primary osteoblasts, as shown by expression of osteocalcin, osteopontin, and bone sialoprotein (BSPII), 21 days after seeding. In vivo implantation in mouse calvaria defects showed significantly more newly mineralized extracellular matrix in the functionalized implant compared to a bare scaffold after 30 days' implantation, as shown by histological scanning electron microscopy/energy dispersive X-ray microscopy study and calcein injection. We have as well bifunctionalized our BMP-7 therapeutic implant by adding human mesenchymal stem cells (hMSCs). The activity of this BMP-7-functionalized implant was again further enhanced by the addition of hMSCs to the implant (living materials), in vivo, as demonstrated by the analysis of new bone formation and calcification after 30 days' implantation in mice with calvaria defects. Therefore, implants functionalized with BMP-7 nanocontainers associated with hMSCs can act as an accelerator of in vivo bone mineralization and regeneration.
\end{abstract}

Keywords: regenerative nanomedicine, electrospun nanofibers implant, nanocontainers of growth factors, BMP-7

\section{Introduction}

Bone regeneration is a complex, well-orchestrated physiological process of bone formation, which can be seen during normal fracture healing, and is involved in continuous remodeling throughout adult life. Nevertheless, there are difficult clinical situations in which bone regeneration is required in large quantities, such as for skeletal reconstruction of large bone defects created by trauma or tumor resection, or in cases in which the regenerative process is compromised (nonunions, osteoporosis). The common bone regeneration techniques used today include the implantation of free fibula vascularized grafts, autologous bone grafts, allograft implantations, and use of growth factors, scaffolds, and osteoprogenitor cells, but all of these are limited. ${ }^{1}$ The tissue engineering approach is a promising strategy in the field of bone regenerative medicine which aims to generate new functional tissues, rather than just to implant nonliving scaffolds. ${ }^{2}$ This alternative could overcome the limitations of current therapies, by combining the knowledge in orthopedic surgery with materials science and
Correspondence: Nadia Benkirane-Jessel UMR I 109, INSERM, Faculté de Médecine, Université de Strasbourg, II Rue Humann, 67085, Strasbourg. France

Tel +33 368853376

Email nadia.jessel@inserm.fr
International Journal of Nanomedicine 20 I5:10 106 I-1075 
biology, and its clinical application offers great potential. ${ }^{2-4}$ For example, distraction osteogenesis and bone transport requiring long treatment possibly have an effect on patients' psychology. Bone grafting requires additional surgical procedures, leading to discomfort for the patient, and is limited by the availability of bone. Bone graft substitutes like metals exhibit poor integration, and beta-tricalcium phosphate or ceramics are brittle. ${ }^{2-4}$ For these reasons, adding cells to materials represents an alternative solution for efficient and robust bone repair. ${ }^{2-4}$ Basically, bone tissue engineering combines progenitor cells, such as mesenchymal stem cells (MSCs) (native or expanded) or mature cells (osteoblasts) seeded in biocompatible scaffolds and ideally in three-dimensional tissue-like structures with appropriate growth factors like bone morphogenetic proteins (BMPs) in order to generate and maintain bone natural regeneration. ${ }^{5}$

To date, three polymer processing technologies (selfassembly, phase separation, and electrospinning) allow the fabrication of nanofibrous scaffolds. ${ }^{6-9}$ Our strategy for regenerating bone combines a synthetic electrospun nanofibrous membrane (ENM) composed of the US Food and Drug Administration (FDA)-approved poly( $\varepsilon$-caprolactone) (PCL) polymer, and the bioactive growth factor BMP-2 entrapped into polymer nanoreservoirs built atop the nanofibers according to layer-by-layer (LbL) technology and fortified. ${ }^{10-21}$

In bone repair, for a small lesion, we do not need bone substitute, as, at this early stage, the regenerative medicine is suitable for regenerating bone tissue. In regenerative medicine, the European and American authorities have already approved the use of BMP-2 or BMP-7 for bone regeneration applications. For example, Medtronic offers InductOs $^{\circledR}$, which is a basic collagen matrix (of animal origin) soaked in BMP-2 (12 mg), and Stryker offers the same collagen membrane soaked in BMP-7. The efficacy of this kind of combination device is dependent on slow release kinetics of BMPs. This criterion is recognized as the critical, most challenging requirement for combination implants. For efficient bone regeneration, the target cells require a reliable and continuous exposure to growth factors over an extended period of time, until the induction of new bone. The currently available devices are totally unsophisticated in this respect. In contrast, our innovative medical device, with cell contact-dependent delivery from nanoreservoirs, is designed specifically for reliable and sustained availability of BMP-2. 16,21,22 This strategy aims at a dramatic enhancement of therapeutic efficacy at reduced cost.

Recently, we reported the capability of a thin $(50 \mu \mathrm{m}$ thick) electrospun nanofibrous PCL membrane functionalized with nanoreservoirs of BMP-2 to increase the speed of bone regeneration both in vitro and in vivo. ${ }^{21}$ The aim of the present study was to use the same PCL polymer to electrospin a thick nanofibrous membrane (from $700 \mu \mathrm{m}$ to $1 \mathrm{~cm}$ ) for large lesions.

In this study, we chose BMP-7 as growth factor to functionalize the thick PCL membrane. This is the first investigation of combined biodegradable, thick PCL membrane and active molecules for regenerative medicine. We have as well fortified this membrane by adding human MSCs (hMSCs). This hybrid and living implant was then analyzed in term of bone induction and the capability to increase the speed of bone regeneration.

In regenerative medicine, the need for such improved composite grafts is obvious, especially for the management of large bone defects (1-2 cm diameter, 2-4 mm thickness), for which the requirements for grafting material are substantial.

Today, composite grafts that are available include synthetic bone or bioabsorbable scaffolds seeded with bone marrow aspirate or growth factors like BMPs, providing a competitive alternative to autologous bone grafts. ${ }^{23} \mathrm{We}$ report herein a new thick, nanofibrous electrospun PCL implant (700 $\mu \mathrm{m}$ thick) functionalized with low-dose bioactive nanocontainers of BMP-7 and seeded with hMSCs as a new strategy to regenerate robust tissue in large-size bone defects.

Recently, great progress has been made in a new generation of biomaterials based on nanotechnology. Nanofibrous biomaterials play central roles in modern strategies in regenerative nanomedicine. The guidance provided by these biomaterials could facilitate restoration of structure and function in damaged or dysfunctional tissues. Such materials should provide provisional 3D support to interact with cells in ways that control their function, by spatially and temporally guiding the complex cellular processes of tissue formation and regeneration. ${ }^{24-31}$ Synthetic bone regenerative scaffolds have been used and investigated over the last century. Several biomimicking medical devices for regenerative medicine have been inspired from the intricate fibrillar architecture of the natural extracellular matrix (ECM). ${ }^{32}$ Such matrices have already shown remarkable success in tissue engineering applications, examples of which include the reconstruction of a dog urinary bladder, or the regeneration after brain injury in a mouse stroke model..$^{27,33,34}$ However, it is established that inert ECM mimetic scaffolds do not efficiently generate durable tissue repair. ${ }^{27,32,33}$ Therefore, there is a need for materials ensuring the sustained release of active compounds. 
To this end, recent advances in nanotechnology have led to various engineered ECM analogs (electrospun nanofibers) and biomaterials functionalized with active therapeutics (drugs, genes, or growth factors). ${ }^{13,15,16,19,21,35-42}$

Polymer processing technologies such as electrospinning ${ }^{43}$ allow nanofiber formation down to the $10 \mathrm{~nm}$ scale. Recently, we reported that it is possible to incorporate active growth factors (BMP-2, TGF- $\beta 1$ ) as nanoreservoirs to induce bone formation. ${ }^{20,21,44-46} \mathrm{We}$ have also shown that electrospun thin PCL membranes $(50 \mu \mathrm{m})$ increase the speed of bone regeneration when they incorporate BMP-2 within nanocontainers. We also showed no passive uncontrolled release of those growth factors from the active nanocontainers, but an active cell contact-dependent release. ${ }^{21}$ In this study, we used the polymer PCL to manufacture thick electrospun nanofibers as scaffolds.

Electrospun nanofibers have an extremely high specific surface area-to-volume ratio because of their small diameters, and the resulting 3D thick nanofiber implants are highly porous with excellent pore interconnectivity. These unique characteristics reveal nanofiber-based implants with many desirable properties for advanced applications.

Recently, different groups have developed different strategies by using not only PCL and MSCs but also BMPs to induce bone regeneration. Our strategy combines both active nanoreservoirs of BMPs (cell contact-dependent release) and stem cells as a new strategy to increase the speed of bone regeneration. Previously, we used BMPs and primary cells. Concerning the electrospun PCL nanofibrous scaffold, in our previous studies, we used a thin membrane $(50 \mu \mathrm{m})$; in this study, ${ }^{23}$ we used a thick membrane. This system combined thick synthetic ENMs of the FDA-approved PCL polymer and the bioactive growth factor BMP-7 confined atop the nanofibers according to $\mathrm{LbL}$ technology. ${ }^{12}$ The latter consisted of a repeated sequence of simple alternate immersions of the ENM scaffold into 1) a solution of chitosan (CHI), a biocompatible polysaccharide with bone regenerative properties, ${ }^{20,43}$ and 2) a solution of BMP-7 (with rinsing steps between consecutive adsorption steps).

We studied the LbL build-up of the BMP-7-based architectures by means of Quartz Crystal Microbalance with Dissipation monitoring (QCM-D) and inspected the structure of the electrospun nanofiber scaffolds with scanning electron microscopy (SEM). The potency of the BMP-7-loaded nanofibrous scaffolds with regards to bone regeneration was assessed both in vitro and in vivo by inspecting cell adhesion, proliferation and specific gene expression, and bone regeneration after implantation in mice.

\section{Materials and methods} 3D nanofibrous PCL scaffold preparation and BMP-7 nanoreservoir build-up

PCL, analytical grade, was obtained from Perstorp (Malmö, Sweden). A solution of PCL $(23 \% \mathrm{wt} / \mathrm{v}$, in dimethylformamide:methylene chloride $1: 1 \mathrm{v} / \mathrm{v}$ ) was electrospun at high voltage ( $20 \mathrm{kV}$ at the beginning) which was increased during the process ( $26 \mathrm{kV}$ at the end). During the electrospinning process (EC-DIG electrospinning apparatus; IME Technologies, Eindhoven, the Netherlands), the delivery of the PCL solution was controlled at a constant rate of $1.2 \mathrm{~mL} / \mathrm{h}$, in an atmosphere at $35 \%$ humidity at $30^{\circ} \mathrm{C}$. The distance between the needle and the collector was set at $16 \mathrm{~cm}$. The electrospun jet was focused by the use of a poly(methyl methacrylate) 2.5 mm-thick mask drilled with a hole (diameter of $25 \mathrm{~mm}$ ) placed over the conductive collector. The 3D electrospun nanofibers were then kept overnight in a desiccator at $45^{\circ} \mathrm{C}$ to evaporate all residual solvent. For the build-up of the BMP-7 nanoreservoirs, the LbL technique was used. The PCL electrospun scaffold was dipped four times during 15 minutes in alternate solutions of CHI (Protasan UP CL 113; Novamatrix, Sandvika, Norway; $500 \mathrm{mg} / \mathrm{mL}$ ) and BMP-7 (Euromedex, Souffelweyersheim, France; $200 \mathrm{ng} / \mathrm{mL}$ ) in MES buffer (2-N-morpholino ethane sulfonic acid; Sigma-Aldrich Co., St Louis, MO, USA; 0.04 M, $\mathrm{NaCl} 0.15 \mathrm{M})$ at $\mathrm{pH}$ 5.5. Each bath was followed by a rinsing step in a solution of MES buffer $(0.04 \mathrm{M}, \mathrm{NaCl} 0.15 \mathrm{M})$.

\section{Cell culture}

Human primary osteoblasts and human bone marrow MSCs were obtained from PromoCell (Heidelberg, Germany). Osteoblasts were cultured in a specific osteoblast growth medium (PromoCell) containing supplement mix (PromoCell), and $50 \mathrm{U} / \mathrm{mL}$ penicillin and $50 \mu \mathrm{g} / \mathrm{mL}$ streptomycin (Ozyme, Montigny-le-Bretonneux, France). The cells were incubated at $37^{\circ} \mathrm{C}$ in a humidified atmosphere of $5 \% \mathrm{CO}_{2}$. When cells reached subconfluence, they were harvested with trypsin (Ozyme) and subcultured. hMSCs were cultured with MSC growth medium (PromoCell) containing MSC supplement mix (PromoCell), $50 \mathrm{U} / \mathrm{mL}$ penicillin and $50 \mu \mathrm{g} / \mathrm{mL}$ streptomycin. The cells were incubated at $37^{\circ} \mathrm{C}$ in a humidified atmosphere of $5 \% \mathrm{CO}_{2}$. When cells reached subconfluence, they were harvested with trypsin and subcultured.

\section{Cell viability and proliferation}

Cell viability was checked by Trypan blue exclusion test. AlamarBlue $^{\circledR}$ (Thermo Fisher Scientific, Waltham, MA, USA) was used to assess cell proliferation over time. The AlamarBlue $^{\circledR}$ test is a nontoxic, water-soluble, colorimetric 
redox indicator that changes color in response to cell metabolism. In this study, $4 \times 10^{4}$ human osteoblasts and $3 \times 10^{3}$ hMSCs were seeded on top of the PCL scaffolds placed on 48-well plates. After 3, 7, and 21 days of culture, cells were incubated in 10\% AlamarBlue ${ }^{\circledR} /$ Dulbecco's Modified Eagle's Medium (medium without phenol red; Lonza, Levallois-Perret, France) solution in a humidified atmosphere at $37^{\circ} \mathrm{C}$ and $5 \% \mathrm{CO}_{2}$. After 4 hours, $200 \mu \mathrm{L}$ of incubation media were transferred to 96 -well plates and measured at $590 \mathrm{~nm}$ and $630 \mathrm{~nm}$ in order to determine the percentage of AlamarBlue ${ }^{\circledR}$ reduction. Statistical analyses were obtained by the twoway ANOVA test in Excel 2011, Microsoft Office (Microsoft Corporation, Redmond, WA, USA).

\section{In vivo implantation on skulls of nude mice}

In regards to animals and tissues, all procedures were designed in compliance with the recommendations of the European Union (2010/63/EU) for the care and use of laboratory animals.

In regards to ethics, experiments followed current European Union regulations (Directive 2010/63/EU), and were performed according to authorized investigator Dr N Jessel (Director of the Osteoarticular and Dental Regenerative Nanomedicine team), holder of a personal license from Préfecture du Bas-Rhin (number 67-315), who oversaw experiments done on mice. All experiments were done in the Animalerie Centrale de la Faculté de Médecine de Strasbourg with the approval number A 67-482-35 from the Veterinary Public Health Service of the Préfecture du Bas-Rhin, representing the French Ministry of Agriculture, Department of Veterinary Science. For further tissue implantations, all surgery was performed under ketamine and xylazine anesthesia, and all efforts were made to minimize suffering.

The study was run with nude male mice (Crl: NIH-Foxn $1^{\text {nu}}$; Charles River, L'Arbresle, France) 6 weeks of age. The mice were anesthetized with an intraperitoneal injection of $100 \mathrm{mg} / \mathrm{kg}$ of ketamine (VIRBAC Santé Animale; Centravet Centravet, Nancy, France) and injection of $10 \mathrm{mg} / \mathrm{kg}$ of xylazine (Rompun ${ }^{\circledR} 2 \%$;) and animals were placed in ventral decubitus on a heating table, with strict aseptic conditions. After skin incision, two bony defects ( $2 \mathrm{~mm}$ size) were created in the parietal zone of the skull using an electric drill with a sterile round burr under irrigation of sterile normal saline before deposition of two samples of nanofibrous PCL implant (either not functionalized $[\mathrm{NF}]$ or functionalized with nanocoreservoirs of BMP-7 [NR4] and/or hMSCs) and sutured with Ethicon 9/0 (Ethicon France, Issy Les Moulineaux, France). hMSCs were seeded on the implant 2 hours before implantation. The skin was sealed with sutures and the animals' behavior observed after waking up. The mice were sacrificed with an intraperitoneal injection of a lethal dose of ketamine and the samples were extracted after 30 days of implantation.

\section{Histology}

For histology, samples (the implants) were fixed for 24 hours in Bouin-Hollande and embedded in paraffin. Serial sections (7 $\mu \mathrm{m})$ were stained with Mallory's stain. After long-term implantations, the samples were demineralized in 15\% EDTA for 48 hours. After the removal of paraffin wax, sections of the calvaria implants were stained using Mallory coloration over 2 days. The percentage of mineralized area on histological sections was measured with ImageJ software by selecting the mineralized area and total implant area.

\section{SEM}

To analyze the morphology, the scaffolds were gold-coated (Edwards Sputter Coater) after fixation in 2.5\% glutaraldehyde for 2 hours at $37^{\circ} \mathrm{C}$, osmium tetroxide $1 \%$ incubation for 1 hour, and dehydration, and observed with a scanning electron microscope (SEM Hitachi TM1000) in conventional mode (high vacuum).

\section{Immunofluorescence staining}

Samples seeded with human osteoblasts or hMSCs were cultivated for 21 days. Then, they were fixed with 4\% paraformaldehyde for 1 hour, permeabilized with $0.1 \%$ Triton X-100 for 1 hour, and incubated for 30 minutes with Alexa Fluor 546-conjugated phalloidin (Molecular Probes; Life Technologies, Fisher Scientific, Illkirch, France) for F-actin labeling and 5 minutes with 200 nM DAPI (Sigma-Aldrich Co.) for nuclear staining. Bone growth induction was measured by assaying expression of osteopontin, osteocalcin, and BSPII, using polyclonal goat anti-osteopontin (1/200; Santa Cruz Biotechnology Inc., Dallas, TX, USA), polyclonal goat anti-osteocalcin (1/200; Santa Cruz Biotechnology), and monoclonal mouse anti-BSPII (1/200; Santa Cruz Biotechnology Inc.) overnight at $4^{\circ} \mathrm{C}$. After washing with polyphosphate buffer (phosphate-buffered saline [PBS]; Sigma-Aldrich Co.), the samples were incubated with secondary anti-goat or anti-mouse antibodies conjugated to Alexa Fluor 488 (Life Technologies). The samples were observed under an epifluorescence microscope (LEICA DM 4000 B).

\section{Calcein injection}

Subcutaneous injections of calcein $(10 \mathrm{mg} / \mathrm{kg}$; Sigma-Aldrich Co.) in PBS were given on the tenth and third days before necropsy. After 30 days of calvaria implantation, mice were sacrificed, and the samples were extracted. The samples 
were then embedded in Tissue-Tek ${ }^{\circledR}$ OCT (Fisher Scientific, Illkirch, France), frozen at $-20^{\circ} \mathrm{C}$, and cut into sections with a cryostat (Leica JUNG CM3000). Cell nuclei were stained with 200 nM DAPI (Sigma-Aldrich Co.) for 5 minutes. The sections were mounted with anti-fading medium and observed under an epifluorescence microscope (LEICA DM 4000 B).

\section{SEM/energy dispersive X-ray spectroscopy}

The different implants were morphologically and compositionally analyzed using a field-emission scanning electron microscope (Inspect ${ }^{\mathrm{TM}}$ F50; FEI, Hillsboro, Oregon, USA) equipped with an energy-dispersive X-ray spectrometer to map the elemental composition of the samples during the inspection. The surfaces were Pt-sputtered before observation and examined at an accelerating voltage of $10 \mathrm{kV}$ and a working distance of $10 \mathrm{~mm}$. The fiber diameter was measured with ImageJ software. ${ }^{47}$

\section{Nanoindentation}

A Berkovich indenter was used in this study. Nanoindentation cycles are divided currently into three steps: loading, creep, and unloading. In these tests, a linear loading step was carried out to achieve the maximum load per cycle. At the end of loading, the creep step is started. This step is characterized by leaving the applied load constant over a certain time. The last step is the unloading, during which the mechanical properties are measured. The method used to characterize these tests is the Oliver-Pharr method. ${ }^{48}$ The maximum load was distributed from $5 \mathrm{mN}$ to $60 \mathrm{mN}$ (quadratic growth). The loading and unloading time was equal to 30 seconds and the creep time was 50 seconds. At least ten cycles of indentation test were performed at the same area, by increasing the load, to obtain the changes of mechanical properties as a function of the indentation depth. The time between each indentation cycle carried out at the same place was 5 seconds.

\section{Statistical analysis}

Averages and standard deviations were calculated from three repeats on each sample, except for AlamarBlue ${ }^{\circledR}$ quantification, where duplicate readings were performed for each repeat. Error bars on graphs represent standard deviation. A two-way ANOVA test was performed in Excel 2011, Microsoft Office.

\section{Results \\ BMP-7 nanoreservoir construction for osteogenic differentiation}

First, a thick electrospun PCL nanofibrous implant (700 $\mu \mathrm{m}$ thick; fibers $689 \pm 45 \mathrm{~nm}$ in diameter) was manufactured as
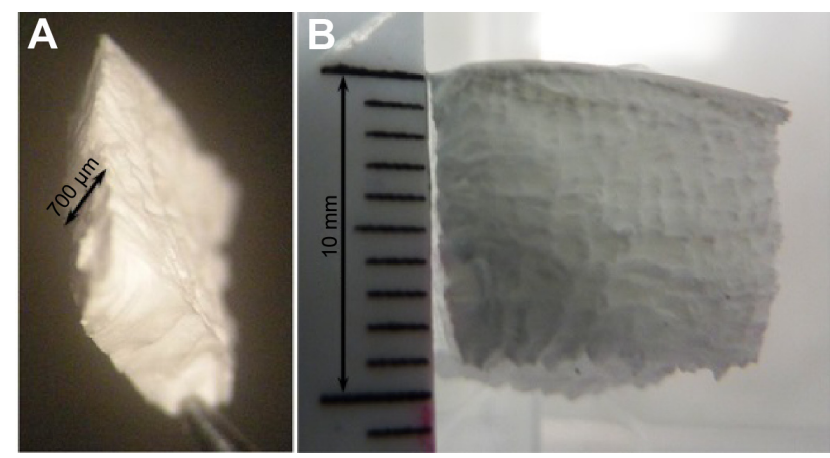

Figure I Macroscopic aspect of thick poly( $\varepsilon$-caprolactone) electrospun nanofibrous membrane.

Notes: $700 \mu \mathrm{m}$ thickness (A) and I cm thickness (B).

scaffold material to generate the tissue-engineered implant (Figure 1). The effective deposition, and nanoscale dimensions, of LbL architectures onto the thick electrospun nanofibrous scaffold were confirmed by means of SEM (Figure 2). While the bare (NF) nanofibers displayed a smooth topography, (CHI/BMP-7) - $_{4}$ treated nanofibers (called NR4) showed uniformly distributed nanostructured deposits on their surfaces. CHI-based deposits had a fish scale-like morphology.

\section{In vitro colonization and osteogenic expression induced by BMP-7 nanoreservoirs}

Before investigating the behavior of the hMSCs, we analyzed the human primary osteoblasts' colonization onto the PCL thick scaffold and their morphology after 3, 7, and 14 days onto this nanofibrous scaffold with or without functionalization with the morphogenetic protein BMP-7 (Figure 3).

To investigate the behavior of human primary osteoblasts in contact with the nanofibrous thick scaffold and the BMP-7 effect, we analyzed the progress of adhesion and colonization of these cells over time. First, the AlamarBlue ${ }^{\circledR}$ reduction percentage, followed over time at 3,7 , and 14 days (Figure 3A), confirmed the viability of the cells on both types of scaffolds (without [NF] or functionalized with [NR4] BMP-7); however, the results do not reveal any significantly enhanced effect of the functionalization $(P>0.05$ at each time and between days 7 and 14). SEM micrographs (Figure 3B) indicate that, already after 3 days, cell adhesion was different for the functionalized (NR4) and NF scaffolds. After 3 days, the osteoblasts adhered onto the NR4 scaffold in clusters, whereas on NF scaffold cells, they were just individually in contact with the nanofibers. However, from day 7 until day 14, cell colonization became similar for both scaffolds, resulting in larger, far more spread and elongated cells 

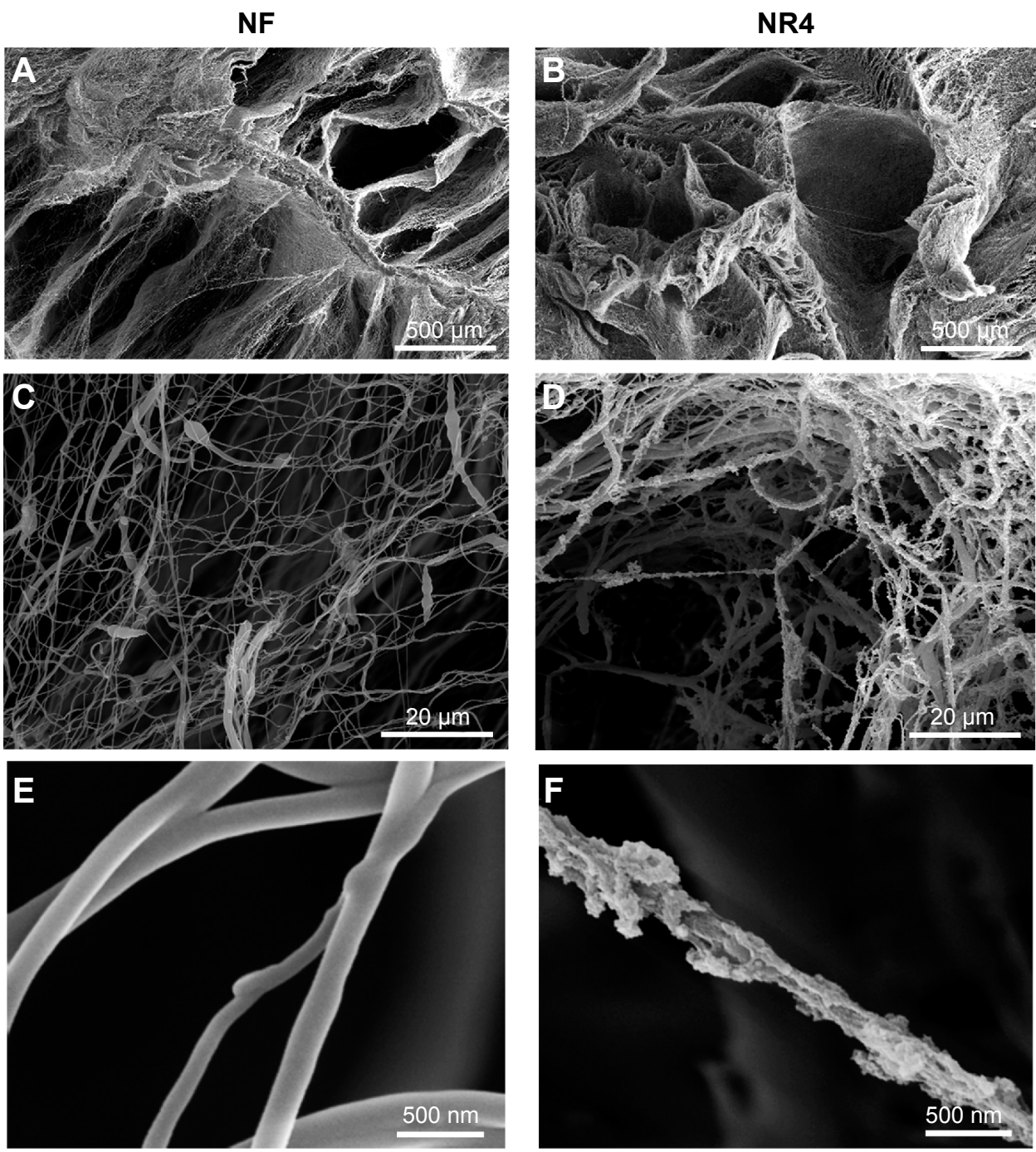

Figure 2 Scanning electron microscopy images of PCL electrospun nanofibrous 3D scaffolds.

Notes: $500 \mu \mathrm{m}$ (A and B), $20 \mu \mathrm{m}$ (C and D), and $500 \mathrm{~nm}$ (E and F) NF and NR4 scaffolds (A, C, and E and B, D, and F, respectively).

Abbreviations: NF, not functionalized; NR4, functionalized with (chitosan/BMP-7) ${ }_{4}$ nanocontainers; PCL, poly( $(\varepsilon$-caprolactone).

anchored to the nanofibers through numerous filopodia extensions, which represent a typical morphology for this kind of cell. To further investigate the extent of bone regeneration, the expression of osteocalcin, osteopontin, and BSPII was examined 21 days after seeding (Figure 4). The immunofluorescence images show that osteogenesis occurs successfully in both types of scaffold (NF and NR4); however, the enhancement of protein expression by the functionalization is significant in vitro, even after 21 days.

\section{BMP-7 nanoreservoirs can accelerate in vivo bone regeneration and mineralization}

To further study matrix synthesis and bone induction, implantations were carried out in vivo in mice. NF and NR4 nanofibrous PCL thick scaffolds were implanted into mouse calvaria defects for 15 or 30 days. At these times, mice were sacrificed and histological study was then carried out to analyze the host cell colonization within the implants in the bone defect site, the osseointegration of the implant, the matrix synthesis, and the new bone mineralization. Mallory coloration was used in order to identify mineralized bone, ECM, and cell nuclei. A difference between NF and NR4 implants could be already seen at the stage of colonization and migration of osteoblasts from the site of implantation within the implants after 15 days of implantation (data not shown). After those days, the host osteoblasts had just begun to migrate inside the NF implant, whereas the colonization within the NR4 implant was clearly higher. Additionally, it appeared that the osteoblasts during migration followed the nanofibers' direction, and no inflammatory reaction was detected. There was even an area showing newly mineralized 
A

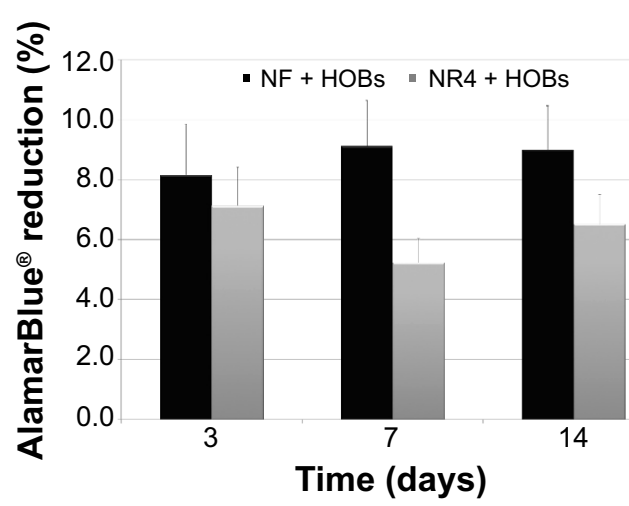

B

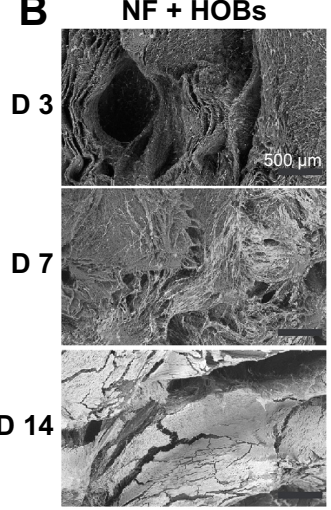

NR4 + HOBs

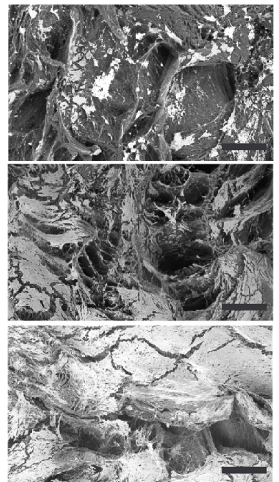

Figure 3 Biocompatibility analysis of the PCL electrospun nanofibrous 3D scaffold in the presence of $\mathrm{HOBs}$.

Notes: $(\mathbf{A}) \%$ AlamarBlue ${ }^{\circledR}$ reduction showing the metabolic activity of the cells at 3,7 , and I 4 days of culture on the $3 D$ scaffolds. $n=9, P>0.05$ each time. Bars $=$ standard deviation. (B) Scanning electron microscopy images of PCL nanofibrous scaffolds (NF and NR4) seeded with human primary osteoblasts after 3, 7, and I4 days. For all images, scale bars $=500 \mu \mathrm{m}$.

Abbreviations: D, day; HOBs, human primary osteoblasts; NF, not functionalized; NR4, functionalized with (chitosan/BMP-7) ${ }_{4}$ nanocontainers; PCL, poly( $\varepsilon$-caprolactone).

ECM, clearly identified (orange staining similar to the native host bone). After 30 days (Figure 5), there was significantly more newly mineralized area within NR4 compared to the NF implant. In order to evaluate the amount of biomineralized matrix in the different implants after 30 days, quantitative measurements were made, showing that only $18 \%$ of the area of the NF implant was mineralized, whereas $31 \%$ for the NR4 implant was achieved.
To further investigate these results, SEM/EDS analysis was used to monitor calcification over time in the in vivo model. The SEM/EDS maps of the implanted scaffolds (Figure 6) showed a clear colocalization of the calcium (Ca) and phosphate $(\mathrm{P})$ signals, indicative of bone formation. To determine the degree of conversion into natural bone 30 days after implantation, the $\mathrm{Ca} / \mathrm{P}$ weight ratios were calculated. The NF and NR4 scaffolds showed ratios of
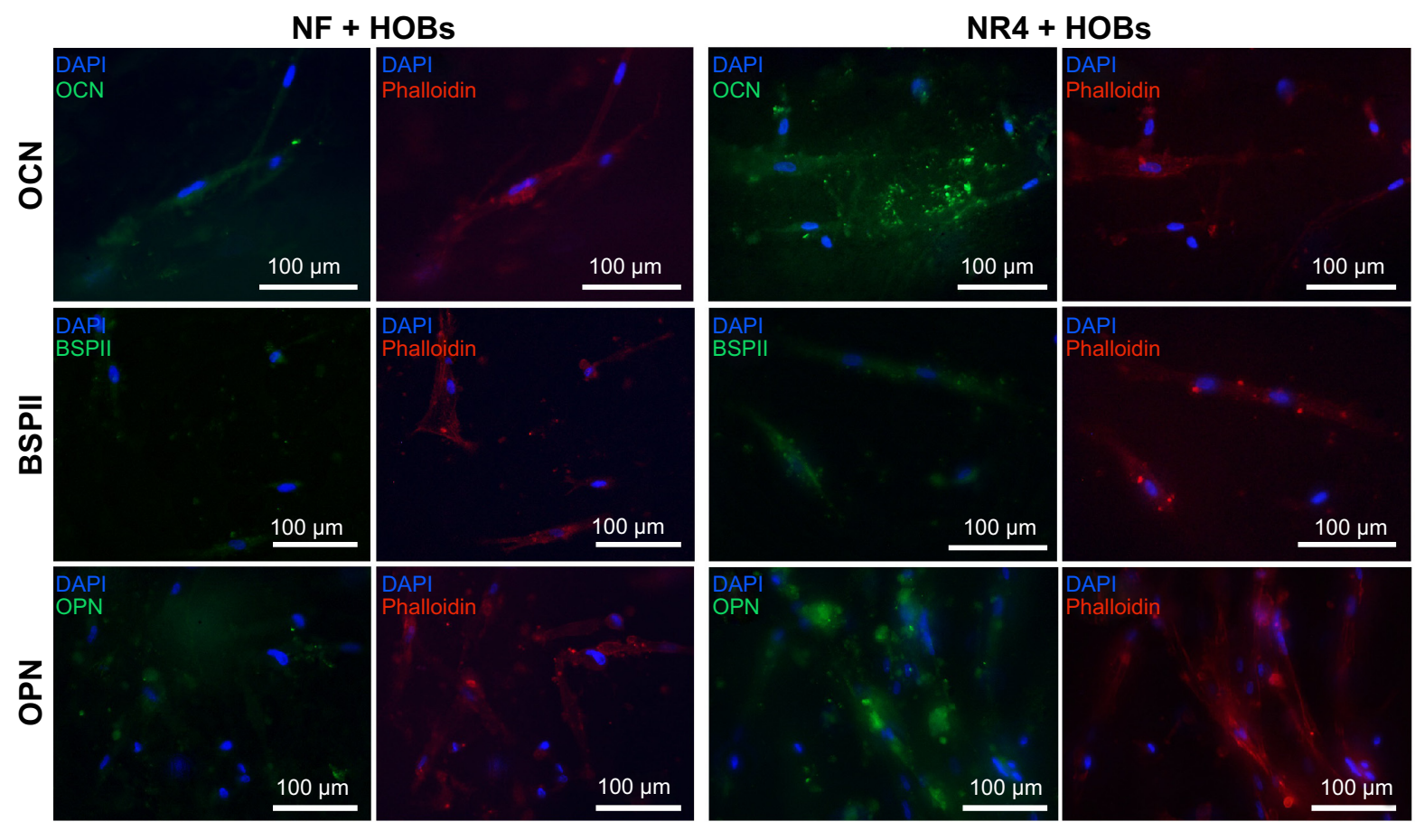

Figure 4 In vitro effect of BMP-7 nanoreservoirs on osteogenic differentiation of human osteoblasts.

Notes: In vitro expression of OCN, BSPII, and OPN in HOBs after 2 I days of cell culture onto the PCL bare scaffolds (NF) or those equipped with BMP-7 nanocontainers (NR4). The nucleus was stained with DAPI (in blue), actin labelled with phalloidin (in red), and OCN, BSPII, and OPN were stained in green. For all images, scale bars $=100 \mu \mathrm{m}$.

Abbreviations: BSPII, bone sialoprotein II; HOBs, human primary osteoblasts; NF, not functionalized; NR4, functionalized with (chitosan/BMP-7) ${ }_{4}$ nanocontainers; OCN, osteocalcin; OPN, osteopontin; PCL, poly(E-caprolactone). 

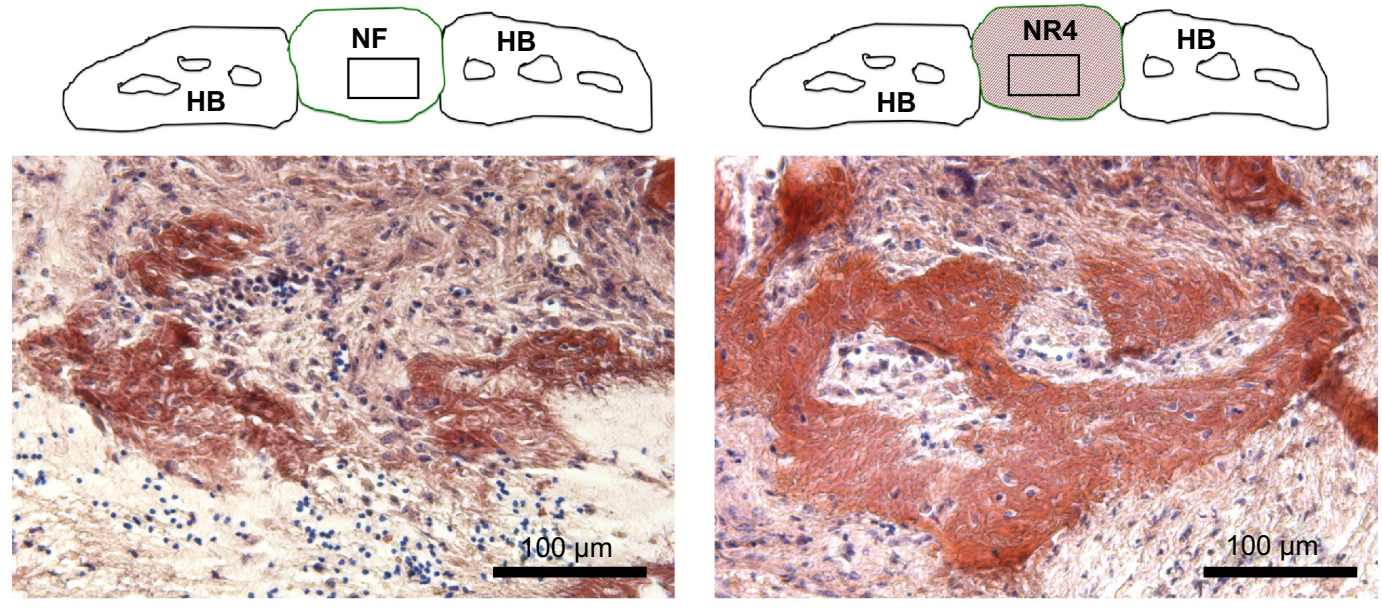

Figure 5 Histological analysis of the effect of BMP-7 nanoreservoirs in vivo on bone tissue regeneration.

Notes: Histological analysis of in vivo bone induction onto functionalized PCL scaffold (NR4) compared to bare PCL (NF) scaffold after 30 days of calvaria implantation in mice. Mallory coloration was used in order to identify mineralized extracellular matrix (pink) and cell nuclei (blue). The square area in the drawn scheme represents the histological section inside the mouse calvaria defects.

Abbreviations: HB, host bone; NF, not functionalized; NR4, functionalized with (chitosan/BMP-7) ${ }_{4}$ nanocontainers; PCL, poly( $(\varepsilon$-caprolactone).

1.10 and 1.75 , respectively (Figure 6A). These results were confirmed by calcein injection after 30 days of culture showing more pronounced mineralization and calcic bone area in the middle part of the NR4 implant (Figure 6B). These results indicate clearly that, by using the thick PCL membrane, after 30 days implantation in the skull of mice, we did not have complete regeneration on the bone defect (Figure 6). That means, by using a thick graft, the functionalization with BMPs only is not enough to sufficiently accelerate the speed of bone regeneration.

To better understand these results, we analyzed the elastic modulus (E) of our retrieved implants (NF and NR4) after 30 days of implantation in mouse calvariae (Figure 7). After this duration, the evolution of the $\mathrm{E}$ as a function of the penetration depth in the (CHI/BMP-7) $)_{4}$-functionalized implant (NR4) and in the implant without functionalization (NF) was followed. First, we observed that, for all tested penetration depths, the values of the $\mathrm{E}$ for functionalized implants (NR4) were always greater than for the NF one. In Figure 7, the crosses illustrate the confidence interval with $95 \%$ of certainty. The regions delimited by each group are clearly separated, indicating that the functionalization was effective, leading clearly to overall enhanced E. We observed that the E decreased with the indentation depth for both implants. At the surface, bone regeneration seems faster than in the bulk. In fact, the implant surface was more easily colonized by host osteoblasts than beneath. When cell adhesion and differentiation were achieved, a high value for the $\mathrm{E}$ at the surface was obtained. Then, it is possible to divide the results of $\mathrm{E}$ into two parts: the surface $(0<$ penetration depth $<5 \mu \mathrm{m}$ ) and the volume (penetration depth $>5 \mu \mathrm{m}$ ). For NR4 and NF scaffolds, the E values varied from $4 \mathrm{GPa}$ in the first microns to $0.70 \mathrm{GPa}$ at a $5 \mu \mathrm{m}$ depth, and from $1 \mathrm{GPa}$ in the first microns to $0.21 \mathrm{GPa}$ at $5 \mu \mathrm{m}$, respectively. For an indentation depth larger than $5 \mu \mathrm{m}$, the $\mathrm{E}$ values seem to be constant: $\mathrm{E}=0.15-0.34 \mathrm{GPa}$ for the NF implant and $\mathrm{E}=0.5-1 \mathrm{GPa}$ for the NR4 implant. As a control, the $\mathrm{E}$ of the native bone was measured. In this case, the $\mathrm{E}$ values varied from 8.2 to $22 \mathrm{GPa}$.

Thus, implants composed of 3D nanofibrous PCL and BMP-7 nanoreservoirs can represent a biocompatible material able to accelerate and improve in vivo bone regeneration and mineralization. To further accelerate the speed of bone regeneration, the third generation of biomaterials should be used, by combining not only growth factors, but also living cells.

\section{BMP-7 nanoreservoirs and hMSCs can improve and accelerate bone regeneration in vivo}

After having analyzed the effect of the 3D PCL nanofibrous scaffold and of the BMP-7 nanoreservoirs on bone regeneration and mineralization in vivo, we investigated if the addition of hMSCs on this functionalized material could improve the efficiency of bone regeneration in vivo.

We first analyzed the potential of hMSCs to infiltrate the PCL thick nanofibrous scaffold in vitro. After seeding hMSCs on the thick NR4 or NF scaffold, we found that cells colonized both NF and NR4 scaffolds, as demonstrated by the AlamarBlue $^{\circledR}$ experiments ( $P>0.05$ at each time) (Figure S1). 


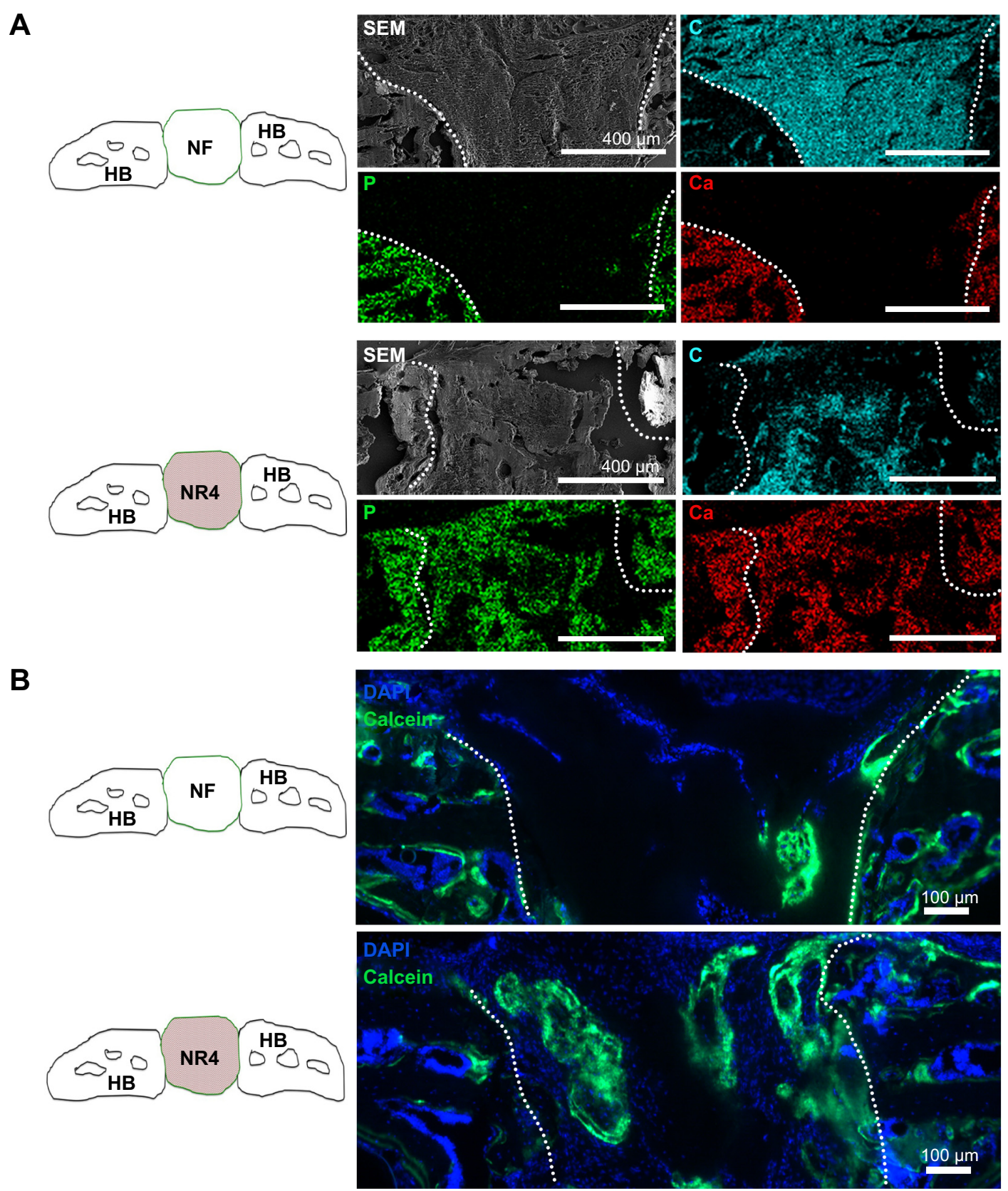

Figure 6 BMP-7 nanoreservoirs' effect in vivo on bone mineralization.

Notes: (A) SEM micrographs, after 30 days of implantation in mouse skull, showing the morphology and composition of the scaffolds; corresponding elemental mapping of P (green), Ca (red), and C (blue) is depicted. Overall SEM visualization of the grafts is in gray. (B) In vivo bone induction onto NF scaffold or onto NR4 PCL scaffold 30 days after calvaria implantations in nude mice. Cell nucleus is in blue, stained with DAPI; bone in formation is shown in green, stained with calcein. For all images, scale bars $=100 \mu \mathrm{m}$.

Abbreviations: C, carbon; Ca, calcium; HB, host bone; NF, not functionalized; NR4, functionalized with (chitosan/BMP-7) ${ }_{4}$ nanocontainers; P, phosphorus; PCL, poly( $\varepsilon$ caprolactone); SEM, scanning electron microscopy.

Although no significant positive effect of NR4 functionalization on hMSC proliferation was found, these results show the biocompatibility of the NR4 3D PCL scaffold with these cells. After 21 days, the immunofluorescence images showed good protein expression of the hMSCs seeded onto both scaffolds (NF and NR4), but again there is no really significant effect of the NR4 architecture in vitro (Figure S2).
To study the ability of hMSCs to improve bone regeneration and mineralization in the functionalized implants in vivo, we analyzed calcification of the implants after 30 days in vivo by SEM/EDS maps (Figure 8). Colocalization of the $\mathrm{Ca}$ and the $\mathrm{P}$ signals was observed on the NF and NR4 scaffolds with hMSCs, obtaining a $\mathrm{Ca} / \mathrm{P}$ weight ratio of 1.35 and 1.65 , respectively. To visualize the formation of 


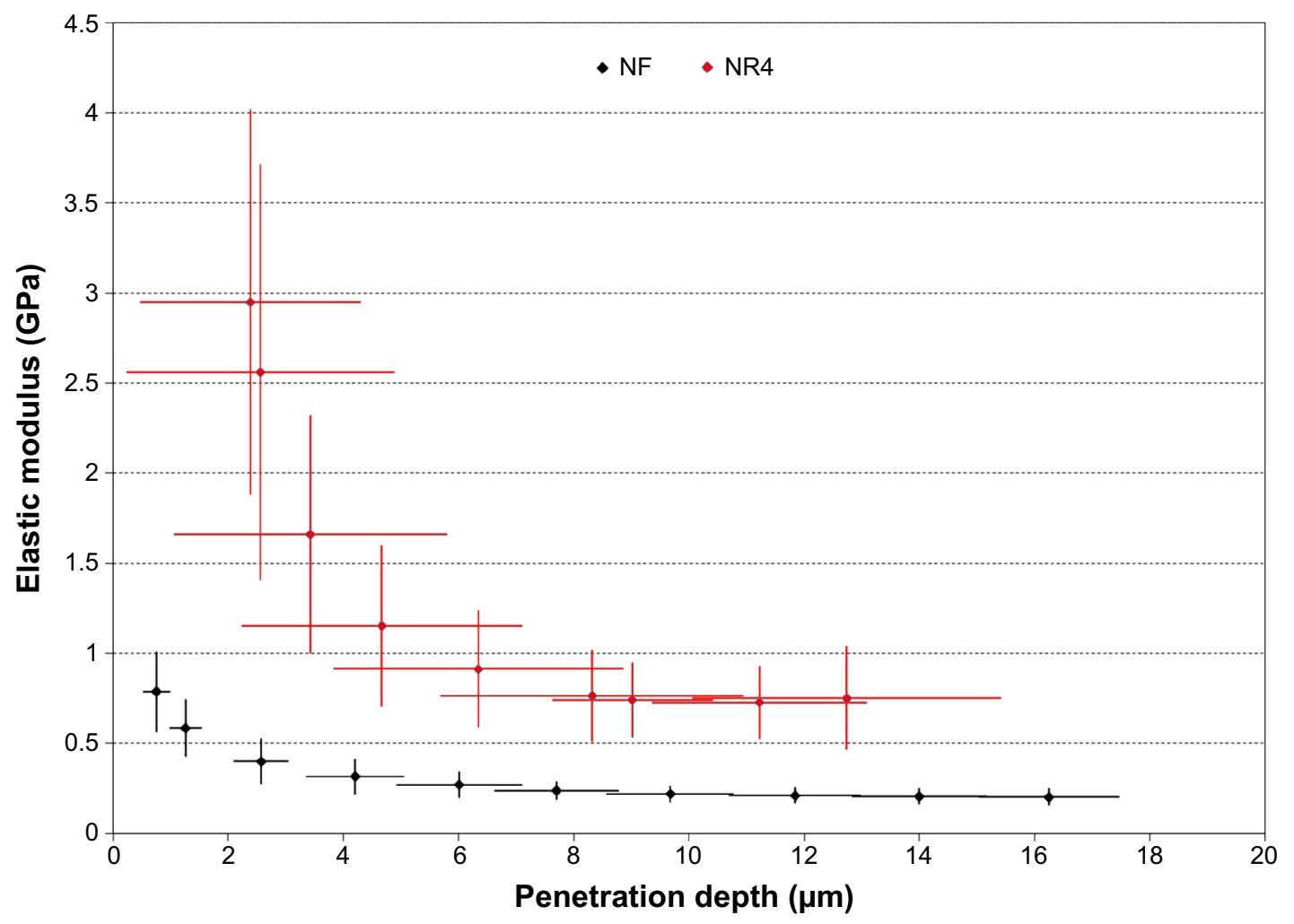

Figure 7 Nanoindentation analysis of the BMP-7 nanoreservoirs' effect on the implants.

Notes: Elastic modulus as a function of penetration depth of nanoindentations carried out on NR4 and NF implants after 30 days' implantation in mouse calvariae. The crosses illustrate the confidence interval with $95 \%$ of certainty.

Abbreviations: NF, not functionalized; NR4, functionalized with (chitosan/BMP-7) ${ }_{4}$ nanocontainers.

new bone, calcein was intraperitoneally injected (Figure 9). Figure 9 shows the positive effect of the NR4 architecture compared to the NF scaffold in the presence of hMSCs. We had already seen a positive effect of the NR4 functionalization compared to bare scaffold in the absence of hMSCs (Figure 6B). However, the supplementary positive effect of the hMSCs can be highlighted when comparing Figure 9 and Figure 6B. Therefore, the double functionalization with BMP-7 and hMSCs can act as an accelerator of in vivo bone mineralization and regeneration.

\section{Discussion}

\section{Thick (CHI/BMP-7) ${ }_{4}$ PCL implant as a} new material for regenerative medicine

In the last decade, a variety of active biomaterials incorporating biological active molecules have been developed. ${ }^{23-49}$ Recently, using an electrospun PCL nanofibrous thin implant, excellent bone regeneration for small lesions was accomplished, with complete colonization and bone induction inside the scaffold after in vivo implantation in mice. ${ }^{21}$ For large lesions, however, the challenge is to develop an approach to induce bone regeneration deep within the implant by using a thick rather than a thin implant.
To achieve robust bone formation on a thick nanofibrous bone implant ( $700 \mu \mathrm{m}$ to $1 \mathrm{~cm}$ thick), we evaluated a new tissue engineering concept combining not only the incorporation of growth factors (BMP-7) within nanoreservoirs, but also hMSCs from bone marrow within electrospun PCL nanofibrous scaffolds. Thus, we evaluated whether bone formation can be further improved by incorporating living hMSCs into the electrospun thick nanofibrous implant.

Electrospun nanofibers have an extremely high specific surface area, which allows the scaffold to mimic the collagen ECM. The resulting 3D, thick nanofibrous implants are highly porous (above 90\%) with excellent pore interconnectivity showing a superposition of thin nanofiber layers. Interactions between the different nanofiber layers occur randomly during the electrospinning process, which leads to a random pore size distribution. These unique characteristics of nanofiber-based implants are desirable properties for advanced applications. ${ }^{21}$

\section{Thick (CHI/BMP-7) ${ }_{4}$ PCL nanofibrous implant for bone regeneration}

The characterization of the thick PCL electrospun scaffold showed a highly porous organization with a structure 

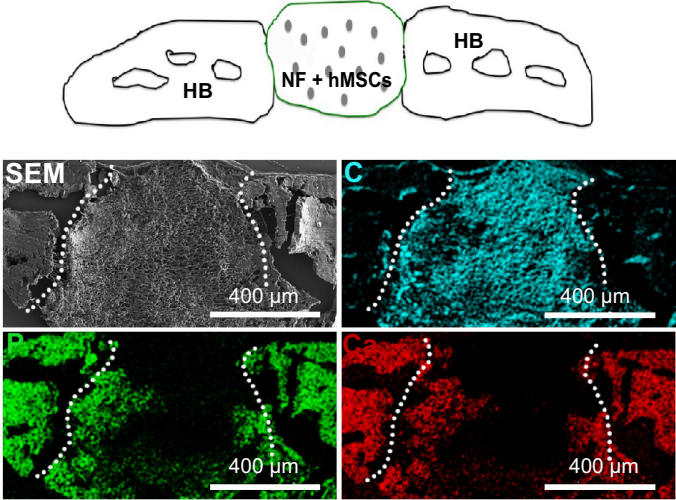
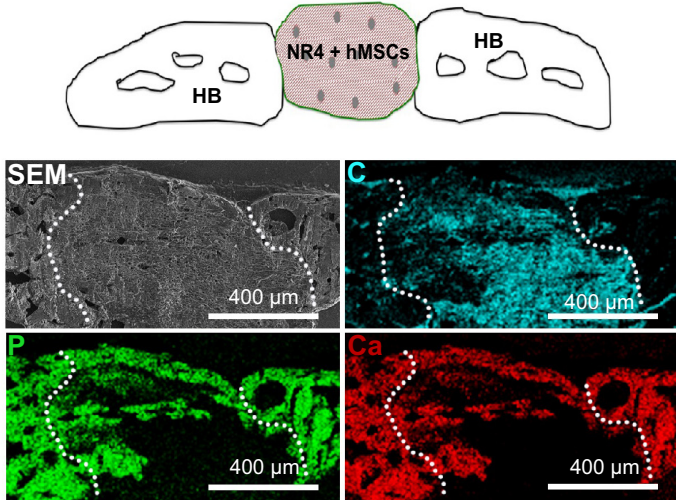

Figure 8 In vivo analysis of combined BMP-7 and hMSCs on bone tissue calcification.

Notes: SEM micrographs showing the morphology and elemental composition of the NF and NR4 scaffolds seeded with hMSCs after 30 days of implantation in mouse skull. Elemental mapping of $\mathrm{P}$ (green), $\mathrm{Ca}$ (red) and C (blue) is depicted. Overall SEM visualization of the grafts is in gray. For all images, scale bars $=400 \mu \mathrm{m}$.

Abbreviations: C, carbon; Ca, calcium; HB, host bone; hMSCs, human mesenchymal stem cells; NF, not functionalized; NR4, functionalized with (chitosan/BMP-7) nanocontainers; P, phosphorus; SEM, scanning electron microscopy.

composed of a superposition of thin nanofibrous layers. Interactions between the different nanofibrous layers occurred randomly during the electrospinning process, which leads to a random distribution of the pores in terms of size. However, because of the interactions between the nanofibrous layers, the pores were not round but presented an elongated shape. Moreover, the elongated filopodia intimately anchored to the nanofibers confirmed a high compatibility between human primary osteoblasts and this thick electrospun nanofibrous PCL scaffold. These results are in agreement with previous literature. ${ }^{43}$ However, it seemed that the infiltration of the cells into the porous structure was relatively limited, particularly on day 14 when the cells were at confluence forming a cell film onto the surface of the scaffold, limiting the infiltration of cells deeply inside.
We also analyzed the osteogenic differentiation of the human osteoblasts and hMSCs in the presence of (CHI/BMP-7) nanoreservoirs. Osteopontin and BSPII are proteins secreted in an early stage of the bone formation process, thus their expression onto both NF and NR4 scaffolds shows that bone formation was accelerated for human osteoblasts by the scaffold structure. However, the in vitro analysis does not enable us to conclude that the functionalization of the thick nanofibrous PCL scaffold with (CHI/BMP-7) nanocontainers has an enhanced effect on bone induction compared to the bare scaffold.

After in vivo model experimentation, however, our results evidently confirmed excellent osteoinduction of our 3D nanofibrous implants. After 30 days' implantation, colonization, migration, and even mineralization had already occurred deep
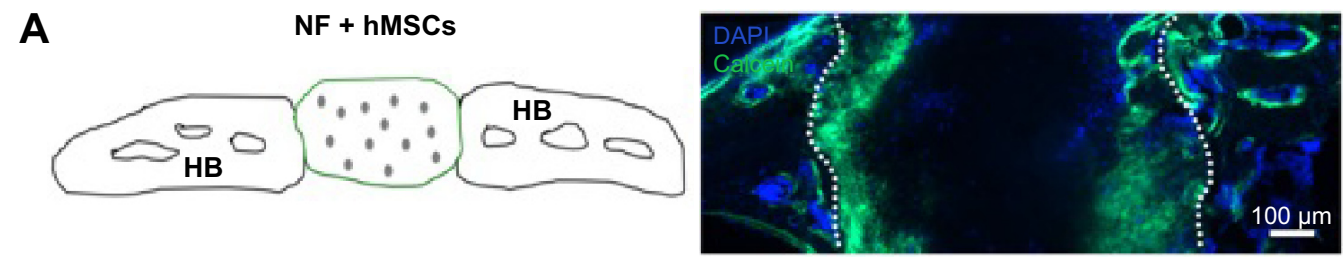

B
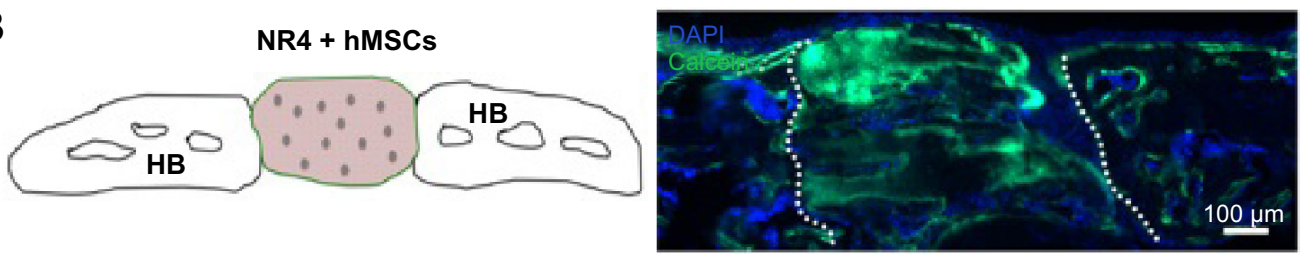

Figure 9 In vivo analysis of BMP-7 nanoreservoirs' and hMSCs' effect on bone tissue mineralization.

Notes: In vivo bone induction onto NF PCL scaffold with hMSCs (A) or onto NR4 PCL scaffold with hMSCs (B) 30 days after calvaria implantation in nude mice. Cell nucleus is in blue, stained with DAPI; bone in formation is shown in green, stained with calcein. For all images, scale bars $=100 \mu \mathrm{m}$.

Abbreviations: HB, host bone; hMSCs, human mesenchymal stem cells; NF, not functionalized; NR4, functionalized with (chitosan/BMP-7) ${ }_{4}$ nanocontainers; PCL, poly( $\varepsilon$ caprolactone). 
inside the implant within NR4 compared to NF thick implants (Figure 5, pink area), meaning that an accelerating effect of the $(\mathrm{CHI} / \mathrm{BMP}-7)_{4}$ functionalization occurred. The results showed that the acceleration effect of the (CHI/BMP-7) functionalization positively affected the NR4 implant. In vivo implantations confirmed that our thick PCL scaffold is biocompatible and nontoxic for living organisms. It was well integrated by the host, and, after 30 days of implantation, new biomineralized area was detected in the scaffold. The $\mathrm{Ca} / \mathrm{P}$ values suggest that the presence of $\mathrm{CHI} / \mathrm{BMP}-7$ nanoreservoirs enhances bone induction. These results could be explained by the increase in the bone regeneration speed due to the treatment with CHI/BMP-7. Our results clearly indicate that, by the incorporation of BMP-7 as nanoreservoirs for cells, bone regeneration was accelerated three times after 30 days; however, complete bone regeneration was not yet achieved (Figure 6). We have as well shown that results in the nanoindentation experiments for the NR4 implant is greater compared to the NF implant. This could be explained by the action of the active nanoreservoirs of BMP-7 onto the nanofibers of the NR4 implant (Figure 3) during cell colonization, differentiation, and bone growth. However, after 30 days' implantation, using the thick implant, the bone regeneration is still not sufficient. To further accelerate the speed of bone regeneration, we combined both growth factors and living cells. In this study, hMSCs derived from bone marrow were used to improve robust bone formation.

\section{Thick PCL nanofibrous implant equipped with BMP-7 and hMSCs to improve robust bone engineering}

The objective of this study was to analyze the ability of the living implants to accelerate osteogenic differentiation and bone regeneration. For this aim, we used thick PCL nanofibrous implants seeded with hMSCs derived from bone marrow without or with active nanoreservoirs of BMP-7 and followed bone regeneration in vitro and in vivo in mice. Although expression of BSPII and osteocalcin of hMSCs occurred at an early stage on both scaffolds, the in vitro model does not enable us to establish a significant enhancement effect of the NR4 nanofunctionalization, compared to the bare scaffold. However, in vivo, we have shown that, after adding hMSCs, significant bone growth can be induced by our nanocontainers of BMP-7 (NR4) (Figure 9). Here we must be clear that the absence of bioactive effect, potentially due to $\mathrm{CHI}$ instead of BMP-7, has been previously proved in experiments involving nanoreservoirs of $\mathrm{CHI} / \mathrm{BSA}$ (bovine serum albumin protein). ${ }^{46}$ Interestingly, by seeding our NR4 implant with hMSCs, we found more newly mineralized bone, which covered nearly completely the bone defect. Control groups comprising NR4 scaffold-only implants without adding stem cells resulted only in partial remineralization. These results point to an increase in the bone regeneration speed due to the double functionalization with BMP-7 and living stem cells.

\section{Conclusion}

Nanostructured and living biomaterials, by incorporation of active therapeutics and stem cells, for use in surgical implantations, could lead to shorter recovery times and decreased risk of postoperative infections or other complications. Such innovative technology will improve quality of life and could reduce costs. Herein, we reported the development and therapeutic impact of advanced living implants combining nanostructured biomaterials with hMSCs, which resulted in superior bone formation in vivo throughout a thick electrospun nanofibrous PCL scaffold. The bifunctionalized living implant depicted in this article enables accelerated bone regeneration in vivo, this being a positive aspect to avoid inflammation in the implantation site. Its nanoreservoirs provide a sustainable source of growth factor for the osteoconductive cells, which is financially and physiologically beneficial for the future patient, as it enables efficient low-dose action, compared to current alternatives in the clinic. Above all, it enables regeneration in large-size defects, which was the challenge to tackle. We believe that this double functionalization could lead to a new generation of engineered bone implants. This concept could be used for other tissue engineering applications.

\section{Acknowledgments}

The authors thank Jean-Luc Weickert for his help with SEM acquisition, Hervé Gégout for histology, and Leandro Jacomine and Christian Gauthier for the nanoindentation experiments and analysis. This work was supported by the project NeoTissage and NanoOSCAR from the Agence Nationale de la Recherche (ANR). NB-J is indebted to CHU de Nancy, Hôpital Central, Chirurgie Orthopédique et Traumatologie (Contrat d'interface INSERM vers l'hôpital).

\section{Disclosure}

The authors report no conflicts of interest in this work.

\section{References}

1. Huey DJ, Hu JC, Athanasiou KA. Unlike bone, cartilage regeneration remains elusive. Science. 2012;338(6109):917-921.

2. Salgado AJ, Coutinho OP, Reis RL. Bone tissue engineering: state of the art and future trends. Macromol Biosci. 2004;4(8):743-765.

3. Dimitriou R, Jones E, McGonagle D, Giannoudis PV. Bone regeneration: current conceptsand future directions. BMC Med. 2011;9:66. 
4. Jimi E, Hirata S, Osawa K, Terashita M, Kitamura C, Fukushima H. The current and future therapies of bone regeneration to repair bone defects. Int J Dent. 2012;2012:148261.

5. Giannoudis PV, Einhorn TA. Bone morphogenetic proteins in musculoskeletal medicine. Injury. 2009;40 Suppl 3:S1-S3.

6. Lee JA, Krogman KC, Ma M, Hill RM, Hammond PT, Rutledge GC. Highly reactive multilayer-assembled $\mathrm{TiO}_{2}$ coating on electrospun polymer nanofibers. Adv Mater. 2009;21(12):1252-1256.

7. Barnes CP, Sell SA, Boland ED, Simpson DG, Bowlin GL. Nanofiber technology: designing the next generation of tissue engineering scaffolds. Adv Drug Deliv Rev. 2007;59(14):1413-1433.

8. Yoo HS, Kim TG, Park TG. Surface-functionalized electrospun nanofibers for tissue engineering and drug delivery. Adv Drug Deliv Rev. 2009;61(12):1033-1042.

9. Fioretti F, Mendoza-Palomares C, Helms M, et al. Nanostructured assemblies for dental application. ACS Nano. 2010;4(6): 3277-3287.

10. Tang Z, Wang Y, Podsiadlo P, Kotov NA. Biomedical applications of layer-by-layer assembly: from biomimetics to tissue engineering. $A d v$ Mater. 2006;18(24):3203-3224.

11. Lynn DM. Layers of opportunity: nanostructured polymer assemblies for the delivery of macromolecular therapeutics. Soft Matter. 2006;2:269-273.

12. Decher G. Fuzzy nanoassemblies: toward layered polymeric multicomposites. Science. 1997;277(5330):1232-1237.

13. Jessel N, Atalar F, Lavalle P, et al. Bioactive coatings based on a polyelectrolyte multilayer architecture functionalized by embedded proteins. Adv Mater. 2003;15(9):692-695.

14. Benkirane-Jessel N, Lavalle P, Meyer F, et al. Control of monocyte morphology on and response to model surfaces for implants equipped with anti-inflammatory agent. Adv Mater. 2004;16(17) 1507-1511.

15. Benkirane-Jessel N, Schwinté P, Falvey P, et al. Build-up of polypeptide multilayer coatings with anti-inflammatory properties based on the embedding of piroxicam-cyclodextrin complexes. Adv Funct Mater. 2004;14(2):174-182

16. Jessel N, Oulad-Abdelghani M, Meyer F, et al. Multiple and timescheduled in situ DNA delivery mediated by beta-cyclodextrin embedded in a polyelectrolyte multilayer. Proc Natl Acad Sci U S A. 2006; 103(23):8618-8621.

17. Kim BS, Park SW, Hammond PT. Hydrogen-bonding layer-by-layerassembled biodegradable polymeric micelles as drug delivery vehicles from surfaces. ACS Nano. 2008;2(2):386-392.

18. Benkirane-Jessel N, Lavalle P, Hübsch E, et al. Short-time tuning of the biological activity of functionalized polyelectrolyte multilayers. Adv Funct Mater. 2005;15(4):648-654.

19. Dierich A, Le Guen E, Messaddeq N, et al. Bone formation mediated by synergy-acting growth factors embedded in a polyelectrolyte multilayer film. Adv Mater. 2007;19(5):693-697.

20. Facca S, Cortez C, Mendoza-Palomares C, et al. Active multilayered capsules for in vivo bone formation. Proc Natl Acad Sci US A. 2010;107(8): 3406-3411.

21. Mendoza-Palomares C, Ferrand A, Facca S, et al. Smart hybrid materials equipped by nanoreservoirs of therapeutics. ACS Nano. 2012;6(1):483-490.

22. Leguen E, Chassepot A, Decher G, Schaaf P, Voegel JC, Jessel N. Bioactive coatings based on polyelectrolyte multilayer architectures functionalized by embedded proteins, peptides or drugs. Biomol Eng. 2007;24(1):33-41.

23. Chatterjea A, Meijer G, van Blitterswijk C, de Boer J. Clinical application of human mesenchymal stromal cells for bone tissue engineering Stem Cells Int. 2010;2010:215625.

24. Peppas NA, Langer R. New challenges in biomaterials. Science. 1994;263(5154):1715-1720.

25. Hubbell JA. Biomaterials in tissue engineering. Biotechnology (N Y). 1995;13(6):565-576.

26. Langer R, Tirrell DA. Designing materials for biology and medicine. Nature. 2004;428(6982):487-492
27. Griffith LG, Naughton G. Tissue engineering - current challenges and expanding opportunities. Science. 2002;295(5557):1009-1014.

28. Chaikof EL, Matthew H, Kohn J, Mikos AG, Prestwich GD, Yip CM. Biomaterials and scaffolds in reparative medicine. Ann N Y Acad Sci. 2002;961:96-105.

29. Yang C, Hillas PJ, Báez JA, et al. The application of recombinant human collagen in tissue engineering. Bio Drugs. 2004;18(2):103-119.

30. Kumar G, Tison CK, Chatterjee K, et al. The determination of stem cell fate by $3 \mathrm{D}$ scaffold structures through the control of cell shape. Biomaterials. 2011;32(35):9188-9196.

31. Pullela SR, Andres C, Chen W, Xu C, Wang L, Kotov NA. Permselectivity replication of artificial glomerular basement membranes in nanoporous collagen multilayers. J Phys Chem Lett. 2011;2(16): 2067-2072.

32. Lee J, Cuddihy MJ, Kotov NA. Three-dimensional cell culture matrices: state of the art. Tissue Eng Part B Rev. 2008;14(1):61-86.

33. Dvir T, Timko BP, Kohane DS, Langer R. Nanotechnological strategies for engineering complex tissues. Nat Nanotechnol. 2011;6(1):13-22.

34. Park KI, Teng YD, Snyder EY. The injured brain interacts reciprocally with neural stem cells supported by scaffolds to reconstitute lost tissue. Nat Biotechnol. 2002;20(11):1111-1117.

35. Choi JY, Jung HJ, Park BJ, Joung YK, Park KD, Han DK. Adhesion behavior of chondrocyte and osteoblast on surface-modified biodegradable PLLA films and scaffolds. Polymer Korea. 2012;36(3):357-363.

36. Berth G, Voigt A, Dautzenberg H, Donath E, Möhwald H. Polyelectrolyte complexes and layer-by-layer capsules from chitosan/chitosan sulfate. Biomacromolecules. 2002;3(3):579-590.

37. Hiller J, Mendelsohn JD, Rubner MF. Reversibly erasable nanoporous anti-reflection coatings from polyelectrolyte multilayers. Nat Mater. 2002;1(1):59-63.

38. Jessel NB, Schwinté P, Donohue R, et al. Pyridylamino- $\beta$-cyclodextrin as a molecular chaperone for lipopolysaccharide embedded in a multilayered polyelectrolyte architecture. Adv Funct Mater. 2004;14(10): 963-969.

39. Gangloff SC, Ladam G, Dupray V, et al. Biologically active lipid A antagonist embedded in a multilayered polyelectrolyte architecture. Biomaterials. 2006;27(9):1771-1777.

40. Zhang X, Sharma KK, Boeglin M, et al. Transfection ability and intracellular DNA pathway of nanostructured gene-delivery systems. Nano Lett. 2008;8(8):2432-2436.

41. Lee J, Kotov NA. Notch ligand presenting acellular 3D microenvironments for ex vivo human hematopoietic stem-cell culture made by layer-by-layer assembly. Small. 2009;5(9):1008-1013.

42. Shim BS, Podsiadlo P, Lilly DG, et al. Nanostructured thin films made by dewetting method of layer-by-layer assembly. Nano Lett. 2007;7(11):3266-3273.

43. Kenawy el R, Layman JM, Watkins JR, et al. Electrospinning of poly(ethylene-co-vinyl alcohol) fibers. Biomaterials. 2003; 24(6):907-913.

44. Eap S, Ferrand A, Schiavi J, et al. Collagen implants equipped with 'fish scale'-like nanoreservoirs of growth factors for bone regeneration. Nanomedicine (Lond). 2014;9(8):1253-1261.

45. Eap S, Keller L, Ferrand A, et al. Nanomechanical properties of active nanofibrous implants after in vivo bone regeneration. Nano Life. 2014;4(1)

46. Ferrand A, Eap S, Richert L, et al. Osteogenetic properties of electrospun nanofibrous PCL scaffolds equipped with chitosan-based nanoreservoirs of growth factors. Macromol Biosci. 2014;14(1):45-55.

47. Eap S, Ferrand A, Palomares CM, et al. Electrospun nanofibrous 3D scaffold for bone tissue engineering. Biomed Mater Eng. 2012; 22(1-3):137-141

48. Kan Q, Yan W, Kang G, Sun Q. Oliver-Pharr indentation method in determining elastic moduli of shape memory alloys - a phase transformable material. J Mech Phys Solids. 2013;61(10):2015-2033.

49. Shah NJ, Hong J, Hyder MN, Hammond PT. Osteophilic multilayer coatings for accelerated bone tissue growth. Adv Mater. 2012; 24(11):1445-1450. 


\section{Supplementary materials}

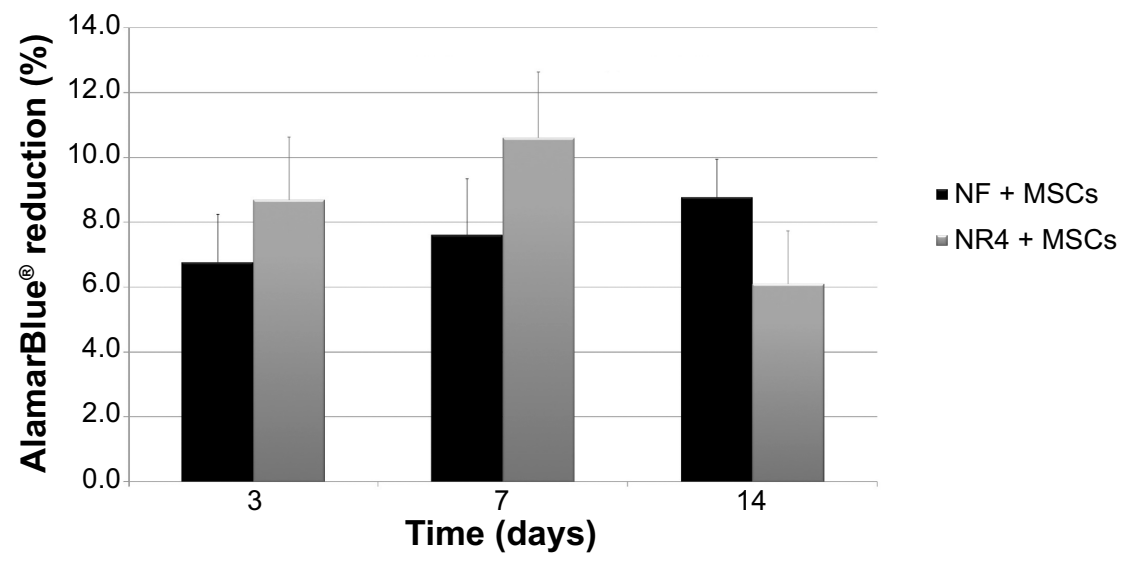

Figure SI In vitro metabolic activity of MSCs on the nanofunctionalized PCL scaffold.

Notes: \% AlamarBlue ${ }^{\circledR}$ reduction on the thick nanofiber implant without BMP-7 (NF) or NR4 implant at 3 days, 7 days, and 14 days. $n=9, P>0.05$ each time. Scale bars $=$ standard deviation.

Abbreviations: MSCs, mesenchymal stem cells; NF, not functionalized; NR4, functionalized with (chitosan/BMP-7) ${ }_{4}$ nanocontainers; PCL, poly( $\varepsilon$-caprolactone).

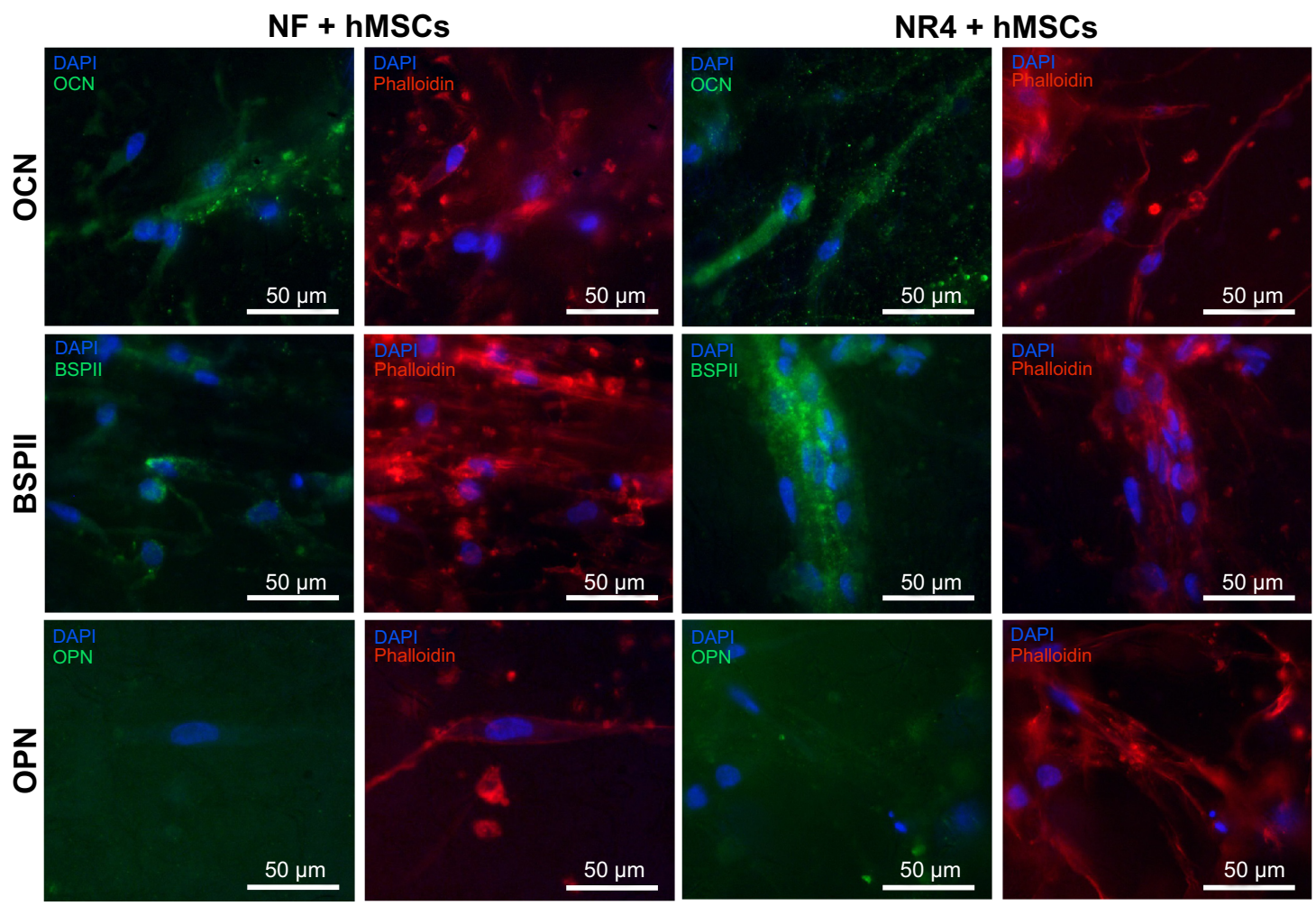

Figure S2 In vitro expression of OCN, OPN, and BSPII in hMSCs after 21 days of cell culture on bare PCL 3D scaffolds (NF) or those equipped with BMP-7 nanocontainers (NR4).

Notes: Nucleus was stained with DAPI (in blue), actin-phalloidin (in red), and OCN, OPN, and BSPII were stained in green. For all images, scale bars $=50 \mu \mathrm{m}$.

Abbreviations: BSPII, bone sialoprotein II; hMSCs, human mesenchymal stem cells; NF, not functionalized; NR4, functionalized with (chitosan/BMP-7) ${ }_{4}$ nanocontainers; OCN, osteocalcin; OPN, osteopontin; PCL, poly( $\varepsilon$-caprolactone). 
International Journal of Nanomedicine

Dovepress

\section{Publish your work in this journal}

The International Journal of Nanomedicine is an international, peerreviewed journal focusing on the application of nanotechnology in diagnostics, therapeutics, and drug delivery systems throughout the biomedical field. This journal is indexed on PubMed Central, MedLine, CAS, SciSearch ${ }^{\circledR}$, Current Contents ${ }^{\circledR} /$ Clinical Medicine,
Journal Citation Reports/Science Edition, EMBase, Scopus and the Elsevier Bibliographic databases. The manuscript management system is completely online and includes a very quick and fair peer-review system, which is all easy to use. Visit http://www.dovepress.com/ testimonials.php to read real quotes from published authors.

Submit your manuscript here: http://www.dovepress.com/international-journal-of-nanomedicine-journal 